\title{
Access and allocation in earth system governance: lessons learnt in the context of the Sustainable Development Goals
}

\author{
Joyeeta Gupta ${ }^{1,2} \cdot$ Louis Lebel $^{3}$
}

Accepted: 7 May 2020 / Published online: 26 May 2020

(c) The Author(s) 2020

\begin{abstract}
Researching socio-ecological justice issues in earth system governance can be operationalized through an Access (securing minimum needs) and Allocation (allocating the remaining resources, responsibilities and risks) framework. This paper synthesizes the review articles in this special issue. It concludes that (a) although international trade, investment and aid aim to enhance access, efficiently allocate resources and reduce risk, in practice the volume of trade and investment, the geographical distance between production and consumption, the pursuit of competitiveness and use of market instruments have concentrated wealth at great cost to socio-ecological justice; (b) research on food, water, energy, climate change and biodiversity reveal multiple linkages among the sustainable development goals, underlining the limitations of sectoral and incremental approaches to socio-ecological justice, for example, for smallholders; (c) while access issues are becoming difficult for politicians to ignore, allocation issues are being side-stepped because they draw too much attention to the underlying causes of inequality and poverty, (d) corrective justice is not enough, substantive justice approaches are needed emphasizing a rights-based framework and allocation cannot be exclusively left to market forces and mechanisms when it concerns public and merit goods; and (e) the terms access and allocation, although individually used, are not popular as a paired framework in the socio-ecological justice literature, but remain highly salient and cover the key justice issues for improving earth system governance.
\end{abstract}

Keywords Access · Allocation · Environmental justice $\cdot$ Social justice $\cdot$ Equity $\cdot$ Planetary boundaries $\cdot$ Social floors $\cdot$ Sustainable Development Goals

\section{Abbreviations \\ ESG Earth system governance \\ SDGs Sustainable Development Goals \\ MEA Multilateral environmental agreements \\ ICT Information and communication technology}

Joyeeta Gupta

j.gupta@uva.nl

1 Amsterdam Institute of Social Science Research, University of Amsterdam, Amsterdam, The Netherlands

2 IHE Delft Institute for Water Education, Delft, The Netherlands

3 Department of Social Science and Development, Ching Mai University, Chiang Mai, Thailand 
NCP Nature' contributions to people

CBDR Common but differentiated responsibilities

SI Special issue

\section{Introduction}

The first science plan of the earth system governance (ESG) programme identified five analytical problems (architecture, agency, adaptiveness, accountability and access and allocation) and four cross-cutting themes (power, knowledge, norms and scale) (Biermann et al. 2010). Socio-ecological justice issues were subsumed under access and allocation. This special issue (SI) on Access and Allocation reviews the literature since 2008 and includes a few key references prior to that date to identify key lessons. It includes papers on trade, aid, investment, climate change, energy, food, water, waste, biodiversity and the interrelations or nexus between them. This concluding paper synthesizes the findings.

Before delving into the synthesis, we note that since 2008, access and allocation scholarship has been influenced by three global events. First, the 2008 financial crises reduced economic activity and related pollution but also exacerbated economic and social hardship. Second, the Paris Agreement on Climate Change (PA 2015) was adopted in 2015 and included a global target on climate change mitigation, adaptation and called for coherence in global financial flows - which occurs through trade, investment and aid. Third, the United Nations General Assembly also adopted the Sustainable Development Goals (SDGs) in 2015 combining goals to protect ecosystem integrity and social justice (UNGA 2015). The SDGs which represent the outcome of a multi-level bargaining process on global priorities (SI, INEA (2016), 16 (3) explicitly call for leaving no one behind and thus call for research on how this can be achieved. Hence, in the analysis which follows we often return to these events and the associated international agreements, especially, the cross-cutting SDGs.

This paper first elaborates on the concepts of access and allocation linking them to discussions on planetary boundaries and social floors, policy decisions encapsulated within the SDGs, and to broader understandings of justice (Sect. 2). It then discusses the key lessons learnt from the literature on trade, investment and aid (Sect. 3) and from the literature on nature's contributions to people (NCP), including climate change, food, water, biodiversity and nexus issues (Sect. 4). Finally, it draws conclusions about the lessons learnt and the usefulness of access and allocation in analysing justice issues.

\section{Access, allocation and the epistemological foundations of socio-ecological justice}

\subsection{Socio-ecological justice operationalized}

Socio-ecological justice can be operationalized in terms of access and allocation. Access addresses issues of meeting the minimum needs of humans to live a dignified life. Allocation addresses distributing the remaining resources, responsibilities and risks between different social actors (Gupta and Lebel 2010). Access as minimum needs can be linked to the academic scholarship on social floors (Raworth 2012). This scholarship goes beyond seeing minimum needs as related to food and water to also discuss access to energy, health, 
education, income and work, peace and justice, political voice, social equity, gender equality, housing, and networks (Raworth 2017). Many of these social floors have been incorporated into the SDGs which liberally mentions access. For example, Target 1.4 states that: "By 2030, ensure that all... have equal rights to economic resources, as well as access to basic services, ownership and control over land and other forms of property, inheritance, natural resources, appropriate new technology and financial services, including microfinance". We can cluster the interpretation of access in different parts of Agenda 2030 into:

- Access to basic services such as water, food, shelter; energy, transport, infrastructure; health; financial services; and ICT and internet. At the international level, such access refers to science and technology, trade, and access to markets.

- Access to natural resources such as clean water; land and green spaces; and marine resources for artisanal fishers. At the international level, the discussion focuses on access and benefit sharing with respect to biodiversity and genetic resources.

- Access to rights for equal treatment including human rights and gender equality, labour rights, sexual and reproductive health and rights, and procedural rights-access to justice, information and participation in decision making. At the international level, there is discussion of access to participation of Least Developed Countries.

Allocation requires first understanding the quantity and quality of the remaining resources. Such allocation may refer to economic and ecological resources. In discussing ecological resources, we build on the concept of Nature's Contributions to People (NCPs) — which includes material, non-material and regulating contributions (Díaz et al. 2018). To define these remaining ecological resources, we reference the scholarship on planetary boundaries (Rockström et al. 2009; Steffen et al. 2015) which cautions that global overuse of resources may destabilize planetary support systems. The space in between the planetary boundaries and social floors represents the safe and just operational space (the doughnut concept). Figure 1 links access and allocation with planetary boundaries and social floors.

Issues related to allocation are also dealt with in Agenda 2030. Agenda 2030 calls for protecting air, water, oceans, land and biodiversity. It calls for reducing the ecological risks to human health and well-being. It also calls for reducing inequality within and between states; income inequality, inequalities of outcomes and mobilizing partnerships and financial resources. In terms of responsibilities, it calls for shared principles, shared responsibility and common but differentiated responsibilities (CBDR); shared prosperity and wealth, and shared knowledge. However, it does not explicitly mention allocation and redistribution. It implicitly assumes that access can be increased without redistribution mechanisms. While Agenda 2030 recognizes many aspects of access and allocation and innovatively mentions inequality and calls for measuring the environmental footprint per capita, it assumes that economic growth will enable SDG achievement although the term economic growth is mentioned relatively infrequently when compared to development (Gupta and Vegelin 2016). The SDGs are reflected upon in and shape ESG scholarship as reflected in this special issue.

\subsection{Epistemological foundations}

We now discuss the epistemological underpinnings of justice and relate them to access and allocation issues. Kalfagianni and Meisch (this SI) distinguish between: conservative (what 


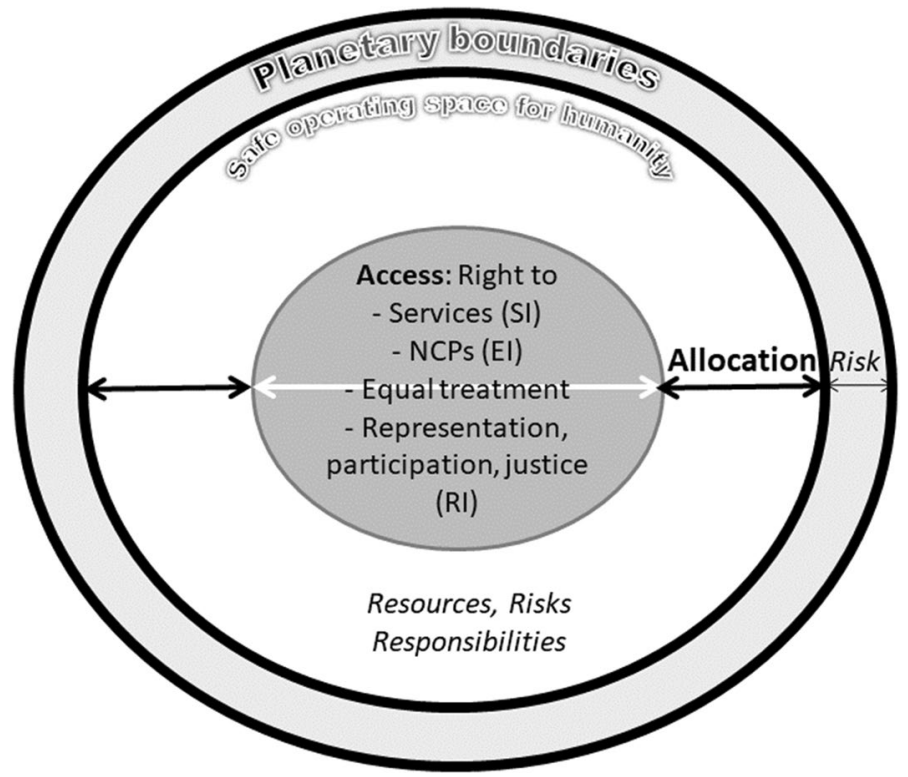

Fig. 1 Access and Allocation in relation to planetary boundaries and social floors. Source: Building on Rockström et al. (2009) and Raworth (2012)

a person could expect) and ideal (what a person should expect) justice; corrective (to remedy a wrong) and distributive (legitimate recipients of rights, responsibilities and risks) justice; and procedural and substantive justice. We use their epistemological understandings to broaden our operationalization of access (to minimum needs, rights, NCP's, services and equality of treatment) and allocation of resources (e.g. through markets or through some equity principles within which markets function), responsibilities (e.g. through the CBDR principle) and risks (e.g. through indemnity and the precautionary principle) building on some of the elements discussed above (see Table 1).

\section{Access and allocation issues in the international economic system}

\subsection{Introduction}

The SDGs call for access to markets, trade, technology and international partnerships to address global challenges and emphasise the difficulties facing least developed countries in the process (see 2.1). Several papers in this SI address access and allocation issues in the global economic system and find that international trade, investment and aid are making it harder to achieve certain goals pointing to limitations in governance and the assumptions behind the SDGs themselves. 


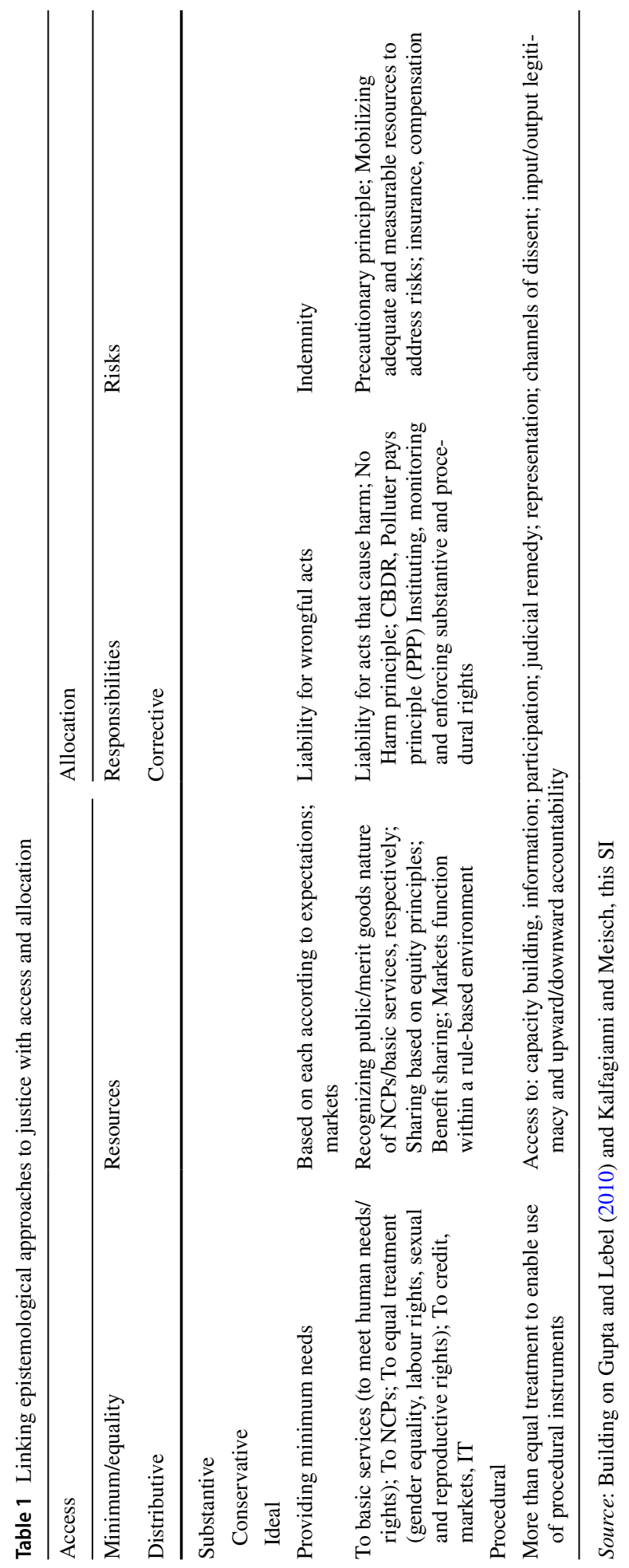




\subsection{Trade}

Trade enhances access to goods and services by reducing their costs. It does so by enabling specialization, competition between actors and ensuring that those with a comparative advantage are able to sell their goods globally. This increases productivity and reduces the prices of goods making them more affordable. However, the overall benefits of trade also raise some socio-ecological access and allocation issues.

Trade negatively affects access to basic resources and increases vulnerability differently in different sectors such as water, food, energy and wastes (Gonenc et al.; Hurlbert; Azizi; Cotta; Ivanova et al.; Scobie; this SI). First, large-scale trade in water and virtual water has affected local water quality, quantity and affordability; large-scale trade in food and fish has affected the local availability and affordability of these commodities for poor people, and large-scale trade in resources and energy has caused both local pollution around mines and factories and global greenhouse gas emissions. Second, trade also indirectly affects access to resources through enlarging socio-economic inequalities that arise from market and financial risks (e.g. price fluctuations, requirements of importing countries, policies of exporting countries, fluctuations in exchange rates, and greater investments in export led-sectors (e.g. cash crops/biofuels) at the cost of others). Trade restrictions can affect the ability of poorer farmers and countries to compete internationally. Finally, trade governance is skewed in favour of those who have greater access to the centralized trade governance system as there is limited scope for public participation and influence. Such governance processes may introduce ideas of participation, transparency and cost-recovery that may further empower the more powerful at the cost of the less powerful people and countries who have a 'capacity gap'. Trade governance may also be influenced by the market mechanisms and trade restrictions promoted by multilateral environmental agreements.

The literature is less explicit on trade's negative impacts on allocation. In terms of its direct impact on allocation of ecosystem benefits and problems, those who consume the goods traded are not affected by the socio-ecological impacts of the extraction and production process elsewhere. Competition, subsidies, tariffs and vertical integration of supply chains may lead to greater exploitation of socio-ecological capital while externalizing impacts. This may lead to a race to the bottom in exporting countries or privilege exporters with modern technologies. In terms of how trade governance allocates rights, responsibilities and risks, since there are many barriers to effective participation by poorer countries and poorer people, their issues seldom get adequately represented in these processes and where they are, they may be only rhetorically or marginally accommodated. In terms of how multilateral environmental agreements affect allocation through trade and investment, the literature shows how this can have detrimental impacts on local people and the environment (Gonenc et al.; Scobie; this SI).

Some lessons learnt from the trade in biofuel and fossil fuel (Ivanova et al.; Azizi; this SI) are that: (a) trade extracts raw materials from the developing world at low prices by externalizing the environment and exacerbating biodiversity loss; (b) trade barriers and liberalization have either reduced local access to resources (e.g. through water privatization, land grabbing, food price volatility, extra-territorial effects of biofuel policies) or exacerbated inequalities (e.g. through tariffs and trade that affect farmers and others); and (c) global supply chains often force producers to produce goods at the cost of local water supplies and other resources and social issues.

Food and fish trade (Azizi; Scobie; Gonenc et al., this SI) show that: (a) the geographical disconnect between areas of production and consumption has affected both 
access to these resources and the allocation of the use of these resources between areas of production and areas of consumption; (b) this disconnect has made poor farmers lose income from food price volatility, and poor consumers cannot afford even small increases in food prices-thus affecting food security; (c) large-scale production has degraded land that affects 3.2 billion smallholder farmers and large-scale fish exploitation supported, e.g. by European Union subsidies has affected the fish security of small fishers and those dependent on fish protein; (d) instruments such as certification may enhance fish (and forest) protection but often exclude small fishers (and smallholders) with low production volumes, limited capacities and low income which hinders their participation in such schemes; (e) subsidies to farmers and fishers in rich countries and competition in food pricing has reduced income for farmers and fishers in poor countries while increased consumption in rich countries; and (e) discourses such as the blue economy and privatization have led to private sector enclosures of the resource rich oceans and 'land grabbing'.

Despite the progress made by the 1987 Basel Convention on the Transboundary Movement of Hazardous Wastes - the waste trade flourishes and wastes continue to move to the Global South. While the idea of the circular economy and the need to treat wastes as resources is important, the question is whether such ideas shifts risks to the poor in the Global South (Scobie; Cotta; this SI). Cotta examines the trade in plastics and electronic wastes. Such trade ostensibly aims to enhance livelihoods, access to resources and recycling in the South. However, papers highlight the socio-ecological damage to humans of illegal and/or legally exported waste; and the implications for the unequal distribution of environmental risks. The electronic market depends on extractive industries, has a quick turnover as electronics become dated and leads to growing wastes. These are exported to the global South for use, reuse, repair and recycling. Although such exports ostensibly aim to address the digital divide and provide affordable resources, the mostly 'near-end-of-life' electronic wastes reaching Africa are often incapable of reuse and repair. This dumping is cost-effective for the North as "high waste management costs in the global North are driving an unscrupulous and unethical e-waste trade with the global South" (Pickren 2014: 113).

With 335 million tonnes of plastic generated annually (PlasticsEurope 2017), plastic wastes are increasing. While reuse and recycling is increasing in Europe, many European countries landfill these wastes or export them (about half of the collected wastes go to Asian countries). Trade in plastic wastes ostensibly allows developing countries to reuse/recycle the wastes. However, this shifts the responsibility to recycle and recover to the South. Where expertise is lacking, these wastes are dumped into rivers and end up in oceans. Single use plastic wastes were exported to China until 2018 when China adopted a law to ban plastic waste imports. This has increased exports to other countries in the Global South. However, some South-East Asian countries are deciding to ship back plastic waste (see Cotta, this SI) reminiscent of the story of the toxic waste shipments of the 1980s.

These experiences challenge simple generalizations on the merits of trade. Furthermore, the need for goods to meet Western standards does not automatically imply that the production processes in the Global South will be cleaned up and although preferential treatment of environmentally friendly technologies can enhance environmental protection, these can also reallocate resources in favour of those with cleaner technologies (Biermann 2014; Biermann et al. 2012; van Asselt and Zelli 2014). Trade also increases the rate at which resources are used and wastes generated and thus can also exacerbate pre-existing inequalities through unfair rules (Tienhaara 2009). 


\subsection{Investment}

Global cooperation is also promoted through investment which can address issues of access and allocation. Following the financial crises in 2008, the banking system came under intense scrutiny, but the expected reforms did not materialize. With the recovery of the global financial system, financial surpluses in different parts of the world needed to be invested elsewhere. For example, multinationals claimed that they can enable a trillion dollar shift to achieve the Sustainable Development Goals (Hoek 2018). Pension funds also have huge resources to invest (Gupta et al., this SI). If such investment is made in areas of public (e.g. ecosystems, stable climate) and merit (e.g. health care, education) goods, it can improve socio-ecological well-being (Scobie, this SI). However, this SI shows that investment may distort access and allocation when investments: (a) serve to increase wasteful consumption in the Global North; (b) externalize socio-ecological impacts on current but also future generations; (c) reproduce past North-South investment patterns (with various forms of neo- and carbon-colonialism) and dump goods, technologies and wastes (including ship-breaking activities) that are destined to become obsolete or problematic on the global South (see below); (d) are accompanied by high-interest loans that may exacerbate the growing new debt crises in the South (the more unstable a country, the higher the interest rates); (e) are written into long-term contracts that are confidential and protected by international investment agreements with few legally binding constraints on investors' behaviour leading them to rely heavily on self-governance such as through corporate social responsibility - which research shows often services public relations' goals rather than addresses the socio-ecological damage caused; and (f) entrench uncritical neo-liberal thinking that has driven global inequities and ecological damage such as land and water grabbing (Gonenc et al.; Scobie; Azizi; Gupta et al.; this SI).

For example, if fossil fuel is to be phased out, fossil fuel investors will face huge economic losses. When large investors divest, their shares are potentially bought by investors mostly from the South who will be left with stranded assets. Export credit agencies which aim at promoting the interests of industries in home countries while addressing development challenges in the developing world are de facto enabling such divestment in the North while transferring the risks to the South with huge economic and ecological consequences while undermining the coherence of financial flows as required by the Paris Agreement on Climate Change (Gupta et al., this SI). Export credits are part of the financial flows from the industrialized countries to the developing world and thus link investment with aid or development cooperation.

\subsection{Aid}

Development cooperation or international aid is a distributive justice tool used by industrialized countries to help developing countries and thus can address access and possibly allocation issues. While there are countless stories of how such development cooperation has succeeded in addressing many challenges in the developing world, especially in terms of food production, health care, humanitarian interventions and ecosystem protection, skeptics increasingly question aid effectiveness (Easterly 2006; Riddell 2007; Visser et al. 2012). This SI shows that aid may lead to adverse inclusion or entrench inequality when: (a) aid misunderstands local contexts; (b) green conditionality exacerbates social injustice or vice versa; (c) aid aims to address socio-ecological aspects but fails to do so in practice-(e.g. 
energy aid studies show that neither the greenhouse gas emissions nor energy poverty were significantly addressed; Bhattacharyya et al. 2018); (d) aid addresses local, symptomatic issues but not the structural global causes; (e) short-term aid relief ignores long-term needs; (f) aid is diverted from development issues to address climate change and is used in an ad hoc, symbolic, gratuitous and paternalistic manner that scarcely reflects the capacity, liability or responsibility of the donors; (g) aid which leads to the North-South movement of potentially stranded assets and wastes; and (h) aid aiming at sustainable development promotes the neo-liberal capitalist agenda and emphasizes growth. The rise of 'celebrity aid' where celebrities focus on certain issues masks the fundamental inequity in the system in a paternalistic focus on addressing symptoms rather than the structural causes. Fragmented aid stands in the way of effective redistribution (Scobie; Gupta et al.; this SI). A possible solution could be a focus on fair outcomes and a legal framework for guaranteeing the quantity and quality of aid; linking disaster relief to climate adaptation; and ensuring input and output legitimacy (Scobie; Grecksch and Klöck, this SI).

\subsection{Key issues}

In theory, trade, investment and aid can enhance access, efficiently allocate resources, improve resource management and reduce risk. In practice, a combination of the volume of trade and investment, the geographical distances between production and consumption, the pursuit of competitiveness and use of instruments such as privatization, certification schemes, permits, trade and investment restrictions and skewed governance processes has often concentrated wealth in the hands of the few at great socio-ecological cost (Table 2).

\section{Access and allocation issues to nature's contributions to people}

\subsection{Introduction}

Moving beyond a discussion of trade, investment and aid, we now discuss access and allocation issues in relation to nature's contributions to people (NCP). In doing so, we recognize that the SDGs have discussed this, inter alia, in terms of climate change, energy, food, water and biodiversity (see 2.1) which provide the context for the discussion below. Agenda 2030 also states that the SDGs interact with varying synergies and trade-offs (Nilsson et al. 2016) connecting decisions in different places calling for systemic and nexus approaches. We now discuss lessons learnt on climate change mitigation (Ivanova et al.; Gupta et al.; this SI) and adaptation (Grecksch and Klöck; Scobie; this SI); energy (Gupta et al.; Ivanova et al., this SI), food (Azizi, this SI), water (Hurlbert, this SI), and biodiversity (Coolsaet et al., this SI). Two key messages emerge-first that while access and allocation issues affect the most vulnerable, vulnerability is not itself a pre-determined fact but results from the way governance in society is structured, and second that these issues are closely related and need to be addressed simultaneously.

\subsection{Climate change adaptation}

In terms of adaptation, climate change can affect access to basic resources (food, water, homes) and harm basic human rights (e.g. through displacement). Climate impacts can exacerbate local vulnerabilities (e.g. when people move to marginal lands) and displace 


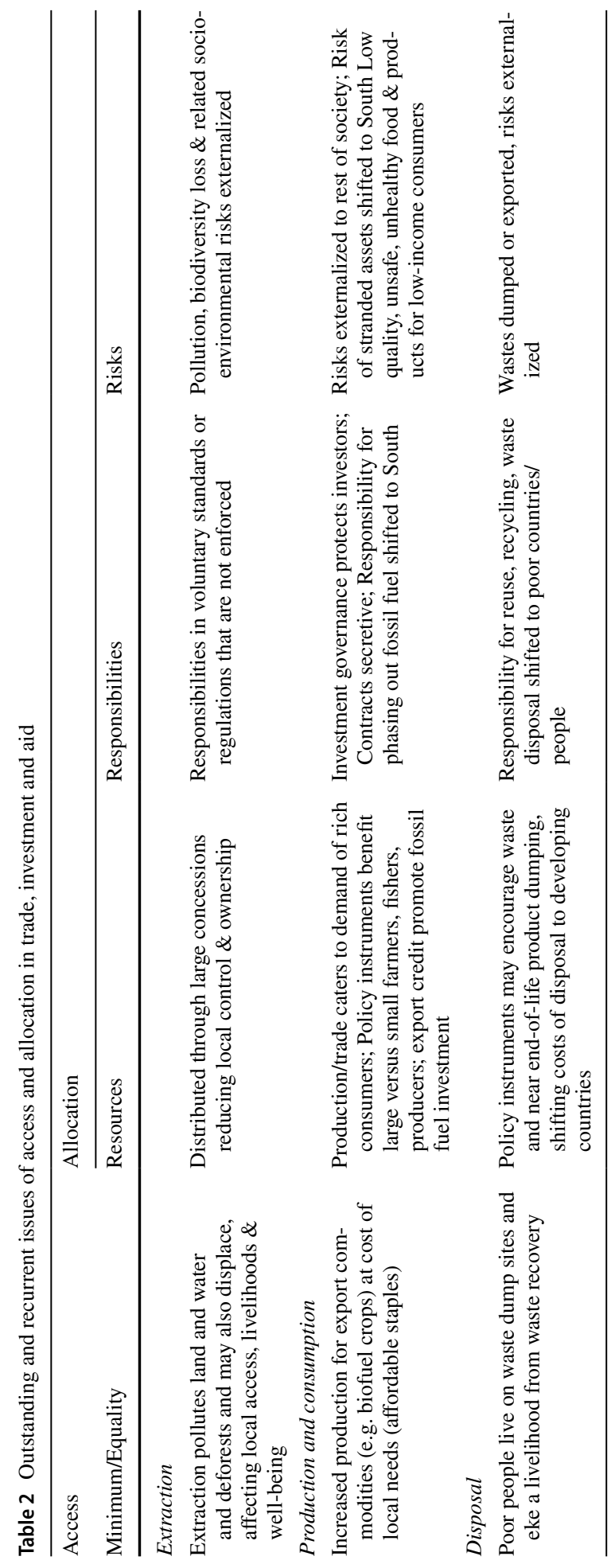


people. Thus, lack of access is linked to increased vulnerability. However, vulnerability is not something generic that can be objectively measured but is produced by political processes. In terms of access to basic rights, climate variability and change may affect people's enjoyment of their human rights and may lead to forced migration; this raises issues of justice on how are the needs and rights of 'trapped populations' (those who cannot migrate) and those who do migrate addressed and who pays for these. And when there are limits to adaptation (residual impacts), who pays for loss and damage. In terms of access to decision making, community-based adaptation is vitally important (although communities also exhibit power differentials), but needs to be supported by higher levels of governance. At the North South level, access of small poorer Southern states to justice with respect to adaptation is an enduring challenge (Grecksch and Klöck; Azizi, this SI).

In terms of allocating resources and related responsibilities and risks with respect to designing, implementing and financing adaptation, the literature argues that such costs should not fall solely on those who are affected, but on those who caused the problem (Cui and Gui 2015; Cui and Huang 2018; Dellink et al. 2009). The question of who should take responsibility and why has been debated over the last thirty years in the literature but remains politically problematic. At the national level, there are discussions regarding who is to be held responsible when people move to more vulnerable sites, and how to ensure that planned and autonomous measures make sense given the uncertainty of the impacts. Global adaptation cost estimates range from USD 4-100 billion annually, but resource generation is slow; there is confusion about which financial transfers qualify as adaptation funding; how this is to be spent; and who benefits from it. While public and private actors are engaged in adaptation, special concerns arise in poorer countries where public actors are less able to govern the private sector in its provision of adaptation services. The scalar gap between the need for adaptation and the levels at which adaptation decisions and finance need to be made and raised, respectively, is another challenge. In examining the allocation of responsibilities on adaptation, the literature has often seen adaptation as a local issue ironically reducing global responsibility while empowering local communities (Grecksch and Klöck; Scobie; this SI). While adaptation aims to minimize risks, it may also exacerbate risks especially in cases of maladaptation. Successful adaptation needs to be effective, efficient, equitable, flexible and is often associated with local ownership, participation and context and cultural relevance; failures are often associated with lack of understanding of the uncertainty in the problem, cultural issues, resources and institutional challenges. Much adaptation may also have externalized impacts on other scales. Children worldwide will bear the largest risks, and their human rights will be affected (Arts 2009), and this is the reason why they are now fighting hard for their rights with the Fridays for Future movement.

\subsection{Climate change mitigation and energy issues}

In terms of access, the need for humans to use energy and food for survival translates into a minimum level of energy use and hence possibly greenhouse gas emissions per capita. A key challenge here is whether the energy transition burdens the poor through expensive alternatives or whether it can be facilitated in a way that it empowers them. In relation to the allocation of resources, responsibilities and risks; papers address these differently. Achieving $1.5-2^{\circ} \mathrm{C}$ requires a rapid fossil fuel phase-out; this means that there is little room to allocate the remaining Carbon emission space to the South as the North itself needs time to phase out its emissions. Distributing the rights to emit greenhouse gases 
within countries equitably, based on energy justice ideas, has been proposed, for instance, in China (Fang et al. 2018). However, the Paris Agreement ultimately opted for a voluntary approach to allocating emission entitlements by promoting Nationally Determined Contributions. Papers in this SI also focus on the territorial and other dimensions of energy resource allocation. Access issues focus on access to energy for the world's poorest; such access can enhance their living standards, well-being and achievement of other SDGs (see Table 3). Correspondingly, problems in relation to access to energy include: (a) the use of unhealthy energy forms by the poorest; (b) the health implications of pollution from the energy extraction process; (c) the health consequence from other energy sources such as radioactive waste from nuclear power generation; and (d) the individual displacement caused by, e.g. hydroelectricity generation, transmission infrastructure, e.g. pipelines, and climate variability and change.

In relation to responsibilities, carbon pricing may encourage the energy transition but might increase the burden on poorer countries. Emissions trading and the clean development mechanism may be efficient but shift the responsibilities for reducing emissions to other countries (Ivanova et al., this SI). Border tax adjustment measures may prevent distortion of WTO rules and enable the energy transition (van Asselt and Zelli 2014). While trade in clean commodities could help to promote sustainable energy, it could transfer economic costs and risks elsewhere (Jinnah and Lindsay 2015). There are no easy answers on biofuels and afforestation as while these address climate change, they may risk other socioecological goals. On risks, the key issue is who bears the risks of stranded resources and assets (i.e. the fossil fuel and related infrastructure) and how will they be compensated for bearing these risks (Gupta et al., this SI). Thus, allocation problems associated with energy relate to: (a) how rights to emissions are allocated worldwide, regionally and locally; (b) how responsibilities with respect to energy production are shared at different levels of governance and the types of instruments developed; and (c) how risks related to energy production, distribution and use are allocated and compensated for. Addressing energy access sustainably thus requires clear engagement with an understanding of energy justice issues and energy governance.

However, such issues are scarcely integrated into the energy and integrated assessment models which often underlie policy decisions. Such models scarcely account for fuel choices, informal economies, supply shortage, traditional biofuel use, the rural-urban divide and the need to assign 'meaningful monetary values' to issues that characterize developing country economies. Many continue to use narrowly defined cost-benefit analysis which is often problematic from a developing country perspective (Ivanova et al., this SI). Some authors instead focus on cost-effectiveness and the right to sustainable development. In terms of the big investors in fossil fuels (pension funds and export credit agencies), a key question is how do their decisions on fossil fuels affect access to affordable/ reliable energy/water, access to a stable climate, clean air, water and land; healthy biodiversity, and access to jobs and pensions. Decisions to engage with shareholders and invest in renewables have all round positive effects as opposed to decisions to divest (Gupta et al.; Ivanova et al.; this SI).

\subsection{Food}

Azizi (this SI) focuses on food security-and shows that food insecurity is not just caused by food shortage but by a failure of food systems. This results from a mismatch between production and consumption systems; long and complex geographically disconnected food 


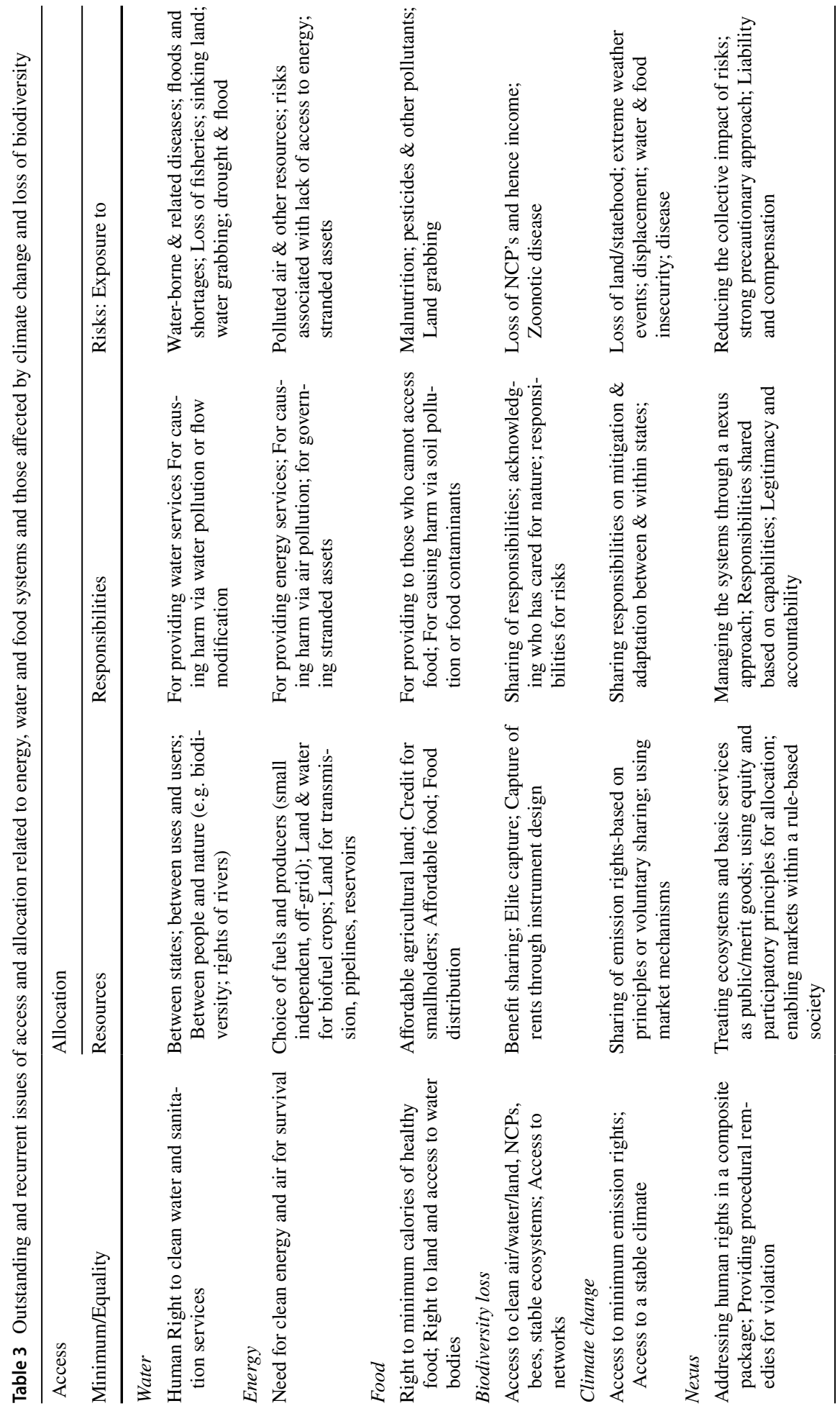


supply chains which enable actors to externalize socio-environmental issues; and climate variability and change. This system affects the ability of poor people to grow or afford healthy food, because of insecure tenure rights, land degradation, climate variability and change, and displacement, and they are also influenced by local pollution. Poor people need to have a human right to a minimum calorie intake, to direct and indirect livelihoods and to some minimum land. Allocation problems associated with food relate to how rights to land tenure/fisheries are allocated and what is produced on land (e.g. biofuel, cash crops). Allocation is affected by 'land grabbing' and 'fish grabbing'; by how responsibilities with respect to food production are shared at different levels of governance between for example small holders/fishers and commercial operations; and how risks related to food production, distribution and use are allocated and compensated for. Achieving availability, affordability, utilization and stability are critical for achieving food security. However, food access governance is institutionally fragmented, lacks a global authority that governs food from all its multiple perspectives and scales, and often bodies like the G20 and dominant multinationals step in but lack the legitimacy (and political will) to make appropriate decisions. Capitalist western style approaches do not match the needs of smallholders. Food security and food sustainability are mutually supportive, and one cannot be achieved without the other.

\subsection{Water}

Access to water is critical for survival, food production and business. The global and national adoption of the human right to water and sanitation services is a first step towards ensuring that all have access. However, marginalised communities are often denied piped connections as they may live in insecure or informal housing or because they cannot afford the services reflecting a growing tension between the human rights approach and the privatization and commodification of water. Access to basic rights needs to be accompanied by access to justice and decision-making, and the literature examines how courts are articulating the human right to water and sanitation. Access to decision-making through participation and deliberative processes needs facilitation through a mandate from the legislature and financial resources which facilitates robust and meaningful participation, reflection and social learning and greater experimentation as opposed to symbolic, ticking the box, participation (Hurlbert, this SI). Water justice authors also focus on the difficulties of small farmers to access water, as a consequence of new technological and infrastructural approaches to provision and management.

In terms of allocating water between different countries, the equitable and reasonable utilization principle in the UN Watercourses Convention addresses this problem. However, the allocation problem is complicated as there is a hard limit to the availability of fresh water (environmental utilization space) and countries and other actors are reluctant to share. Water allocation is also affected by increasing global water 'grabbing'. The allocation of resources can also be influenced by the role of social processes and movements and the way in which technology is developing. In terms of responsibilities, a key issue is with respect to supplying water to different users. Water supply in many parts of the world still fails to meet the basic requirements of safety, quality, reliability, affordability and face key institutional challenges including issues of costrecovery (Schwartz et al. 2018). In terms of risks, there is a huge literature on riparian responsibility for managing river basins and not causing harm to others (see forthcoming SI on the No Harm principle in water law). Water-related risks include floods and 
droughts and those related to accumulated pollution and disaster risk reduction and quality standards are being adopted but remain challenging in practice. This exacerbates problems for vulnerable communities as when policies remain unimplemented, they are often in the front-line. The rise of the idea of the right of the river in different countries is also emphasizing that ecosystems need to be protected for their own sake. Finally, understanding access and allocation to water has to confront the debate on the nature of water-is water a commodity, a commons or a public good (Hurlbert, this SI).

\subsection{Biodiversity}

Biodiversity is critical for the functioning of global ecosystems, and $70 \%$ of the world's poor depend directly on such ecosystems for their survival. Much of global conflict is regarding who gets access to biodiversity and how benefits derived are allocated. Biodiversity protection has shifted from conservation through fences and fines via sustainable use to rights-based conservation approaches in the literature, and the latter aims to ensure that the poorest are able to access their resources and enjoy a fair share of the benefits that flow from using these resources.

Coolsaet et al. (this SI) focus on the Global South and argue that in the context of biodiversity, access refers to access to (and or deprivation of) biological/natural, economic (credit, markets), human (e.g. knowledge, training) and social (e.g. networks) resources/capital; rights to withdraw, manage, exclude and alienate; and other rights and/or access to the benefits of biological resources or NCPs-and access to procedural rights to information, participation and justice. Access is only meaningful when it combines access to different related assets as well as in combination with appropriate allocation.

Allocation refers to (inter)national benefit sharing and is being promoted through instruments such as payments for ecosystem services, protected areas, ecotourism revenue shares, logging permits, production quotas, hunting blocks and compensation for damage caused by wildlife. While benefit sharing was meant to ensure that those who looked after the resources also benefitted from the profits emerging from exploiting the resource, these have been poorly implemented in practice. This is affected by the role of power in allocating access to and allocation of biodiversity resources as local communities are often disempowered and dispossessed of their rights; even decentralization may fail when it does not address elite capture in places where power structures and inequalities are deeply embedded in societies. Well-meaning intentions can lead to adverse inclusion-where ecotourism leads to rising land prices; or protected areas exacerbate poverty. Dominant influential actors include donors, states, multinationals and NGOs who pursue market-based narratives, treat social and ecological issues separately, use single instruments and externalize certain impacts and these do not fit with local aspirations and contexts. Instruments that focus on the conditions of access often ignore the constraints and interests involved and lead to adverse outcomes. In terms of risks, loss of biodiversity may also exacerbate zoonosis-where disease moves from animals to humans-and zoonosis is already $60 \%$ of current infectious disease (Ekins et al. (eds.) (2019)). Further research and social activism is needed to ensure that vulnerable and marginalized groups are meaningfully engaged in the design of local, and inform global, institutions such as the post-2020 framework under the Convention on Biological Diversity. 


\subsection{Key issues}

The SDGs emphasize the need to see all goals as interrelated and interlinked. The papers in this special issue show how closely access to water, food and energy are linked and how they are influenced and influence biodiversity loss and climate change. They also emphasize the need to think systemically about these different issues. Furthermore, global challenges further exacerbate the vulnerability of those who are marginalized, poor and exposed to ecological damage. This requires thinking beyond sectoral silos and integrating issues of sustainability across different fields (Sharma and Kumar, this SI) and addressing the structural institutions that cause and reproduce inequality.

Although key allocation issues vary somewhat across natural resources and the environmental dimensions covered in this SI, our authors emphasize that access is all about rights. Table 3 elaborates on what access means in terms of the different issue areas; and how allocation of resources, responsibilities and risks are addressed.

\section{Conclusions}

The social science community's work on socio-ecological justice has been complemented by the ongoing work on the 'doughnut' that invites the social and natural science communities to work together on achieving the SDGs. The interlinkages between these academic and policy processes have enriched the literature. We now draw some key lessons from this SI.

From a global perspective, the notion of a safe and just operating space is intuitively appealing. What it does not show is in the details: the huge differences between the wealthy and destitute; whether the destitute are themselves the result of global governance systems; and how governance processes of the operating space may be full of contradictions. The papers in this SI note that while most use of global resources and ecosystems results from the growing consumption and investment patterns of the rich, those worst affected are the poor and marginalized. Geographical separation, distorted markets and skewed policy subsidies and instruments exacerbate socio-ecological injustices. Corrective approaches to justice, to right individual wrongs, do not go far enough; what is needed is ideal, distributive, justice which (a) recognizes a rights-based approach to address problems that repeat themselves from issue area to issue area, (b) adopts equitable sharing of resources and (c) does not take an issue-by-issue approach but takes the nexus (bundle) of the issues into account. This has become increasingly apparent in the last decade.

However, while access issues are becoming difficult to ignore, allocation is more challenging. The political arena is more willing to focus on access issues (albeit sometimes paternalistically), for instance, in Agenda 2030 than on re-allocation of resources, responsibilities and rights. Allocation has been driven by a narrow economic growth logic to development, cost-recovery and a reliance on the market. Furthermore, as this SI has shown access and allocation are intertwined and one cannot be achieved without addressing the other.

Authors in this SI have applied the framework directly and indirectly, emphasizing different elements and terminologies. They argue that access and allocation are often difficult to disentangle and sometimes unintuitive for analysing individual issues, as different issues have their own and different terminologies. We acknowledge this. However, disentangling 
enables analysis of individual issues while being treated holistically, and a common access and allocation framework may enable inter-disciplinary assessments of socio-ecological justice across issue areas and is salient to improving earth system governance. A singular emphasis on access (social floors) is paternalistic and avoids the larger question of what caused inequality and poverty in the first place-highly skewed systems of allocation.

Acknowledgements This paper has been written as part of the research work within the Governance and Inclusive Development Programme of the Department of Geography, Planning and International Development Studies, in the Amsterdam Institute for Social Science Research of the University of Amsterdam and IHE-Delft Institute for Water Education.

Open Access This article is licensed under a Creative Commons Attribution 4.0 International License, which permits use, sharing, adaptation, distribution and reproduction in any medium or format, as long as you give appropriate credit to the original author(s) and the source, provide a link to the Creative Commons licence, and indicate if changes were made. The images or other third party material in this article are included in the article's Creative Commons licence, unless indicated otherwise in a credit line to the material. If material is not included in the article's Creative Commons licence and your intended use is not permitted by statutory regulation or exceeds the permitted use, you will need to obtain permission directly from the copyright holder. To view a copy of this licence, visit http://creativecommons.org/licenses/by/4.0/.

\section{References}

Arts, K. (2009). A child rights perspective on climate change. In M. A. Salih (Ed.), Climate change and sustainable development: New challenges for poverty reduction (pp. 79-93). Cheltenham: Edward Elgar.

Bhattacharyya, S., Intartaglia, M., \& McKay, A. (2018). Does energy-related aid affect emissions? Evidence from a global dataset. Review of Development Economics, 22(3), 1166-1194. https://doi.org/10.1111/ rode. 12409 .

Biermann, F. (2014). Earth system governance: World politics in the anthropocene. Cambridge, MA: MIT Press.

Biermann, F., Abbott, K., Andresen, S., Bäckstrand, K., Bernstein, S., Betsill, M. M., et al. (2012). Transforming governance and institutions for global sustainability: Key insights from the Earth System Governance Project. Current Opinion in Environmental Sustainability, 4(1), 51-60. https://doi.org/10.1016/j.cosus t.2012.01.014.

Biermann, F., Betsill, M. M., Gupta, J., Kanie, N., Lebel, L., Liverman, D., et al. (2010). Earth system governance: A research framework. International Environmental Agreements: Politics, Law and Economics, 10(4), 277-298. https://doi.org/10.1007/s10784-010-9137-3.

Cui, L., \& Gui, H. (2015). Sharing the burden of financing the green climate fund in the post-kyoto era. International Journal of Climate Change Strategies and Management, 7(2), 206-221. https://doi.org/10.1108/ IJCCSM-11-2013-0125.

Cui, L., \& Huang, Y. (2018). Exploring the schemes for green climate fund financing: International lessons. World Development, 101, 173-187. https://doi.org/10.1016/j.worlddev.2017.08.009.

Dellink, R., den Elzen, M., Aiking, H., Bergsma, E., Berkhout, F., Dekker, T., et al. (2009). Sharing the burden of financing adaptation to climate change. Global Environmental Change, 19(4), 411-421. https://doi. org/10.1016/j.gloenvcha.2009.07.009.

Díaz, S., Pascual, U., Stenseke, M., Martín-López, B., Watson, R. T., Molnár, Z., et al. (2018). Assessing nature's contributions to people. Science, 359(6373), 270-272. https://doi.org/10.1126/science.aap8826.

Easterly, W. E. (2006). The white man's burden: Why the west's efforts to aid the rest have done so much ill and so little good. Oxford: Oxford University Press.

Ekins, P., Gupta, J., \& Boileau, P. (Eds.) (2019). Global environment outlook-GEO-6: Healthy planet healthy people. Cambridge: Cambridge University Press.

Fang, G., Liu, M., Tian, L., Fu, M., \& Zhang, Y. (2018). Optimization analysis of carbon emission rights allocation based on energy justice: The case of China. Journal of Cleaner Production, 202, 748-758. https://doi. org/10.1016/j.jclepro.2018.08.187.

Gupta, J., \& Lebel, L. (2010). Access and allocation in earth system governance: Water and climate change compared. International Environmental Agreements: Politics, Law and Economics, 10(4), 377-395. https ://doi.org/10.1007/s10784-010-9139-1. 
Gupta, J., \& Vegelin, C. (2016). Sustainable development goals and inclusive development. International Environmental Agreements: Politics, Law and Economics, 16(3), 433-448. https://doi.org/10.1007/s1078 4-016-9323-z.

Hoek, M. (2018). The trillion dollar shift. The trillion dollar shift. London: Routledge. https://doi. org/10.4324/9781351107297.

Independent Evaluation Group, World Bank, International Finance Corporation \& Multilateral Investment Guarantee Agency. (undated). Adapting to Climate Change: Assessing World Bank Group Experience Phase III of the World Bank Group and Climate Change. https://ieg.worldbankgroup.org/sites/default/files/ Data/Evaluation/files/cc3_full_eval.pdf Assessed 23 April 2020

Jinnah, S., \& Lindsay, A. (2015). Secretariat influence on overlap management politics in North America: NAFTA and the commission for environmental cooperation. Review of Policy Research, 32(1), 124-145. https://doi.org/10.1111/ropr.12106.

Nilsson, M., Griggs, D., \& Visbeck, M. (2016). Policy: Map the interactions between sustainable development goals. Nature, 534(7607), 320. https://doi.org/10.1038/534320a.

Pickren, G. (2014). Political ecologies of electronic waste: Uncertainty and legitimacy in the governance of e-waste geographies. Environment and Planning A, 46(1), 26-45. https://doi.org/10.1068/a45728.

PlasticsEurope. (2017). Plastics-the Facts 2017: An analysis of European plastics production, demand and waste data. https://www.plasticseurope.org/en/resources/publications/274-plastics-facts-2017. Assessed 23 April 2020

Raworth, K. (2012). A safe and just space for humanity- Can we just live within the donut. Oxfam Discussion Papers, 1-26. https://www.oxfam.org/en/research/safe-and-just-space-humanity. Assessed 23 April 2020

Raworth, K. (2017). A Doughnut for the Anthropocene: humanity's compass in the 21st century. The Lancet Planetary Health, 1(2). Elsevier. https://doi.org/10.1016/S2542-5196(17)30028-1.

Riddell, R. C. (2007). Does foreign aid really work?. Oxford: Oxford University Press.

Rockström, J., Steffen, W., Noone, K., Persson, A., Chapin, F. S., Lambin, E. F., et al. (2009). A safe operating space for humanity. Nature, 461, 472-475. https://doi.org/10.1038/461472a.

Schwartz, K., Gupta, J., \& Tutusaus, M. (2018). Inclusive development and Urban Water Services. Habitat, 73, 96-100.

Steffen, W., Richardson, K., Rockström, J., Cornell, S. E., Fetzer, I., Bennett, E. M., et al. (2015). Planetary boundaries: Guiding human development on a changing planet. Science, 347(6223), 1259855. https://doi. org/10.1126/science. 1259855 .

Tienhaara, K. (2009). The expropriation of environmental Governance protecting foreign investors at the expense of public policy. Cambridge: Cambridge University Press.

UN General Assembly. (2015). Transforming our world: the 2030 Agenda for Sustainable Development. A/ RES/70/1. https://www.un.org/en/development/desa/population/migration/generalassembly/docs/globa lcompact/A_RES_70_1_E.pdf. Assessed 23 April 2020

van Asselt, H., \& Zelli, F. (2014). Connect the dots: Managing the fragmentation of global climate governance. Environmental Economics and Policy Studies, 16(2), 137-155. https://doi.org/10.1007/s1001 8-013-0060-z.

Visser, R., L. Shulpen \& W. Elbers (2012). De hulp voorbij? Op zoek naar internationale samenwerking. KIT Publisher.

Publisher's Note Springer Nature remains neutral with regard to jurisdictional claims in published maps and institutional affiliations. 